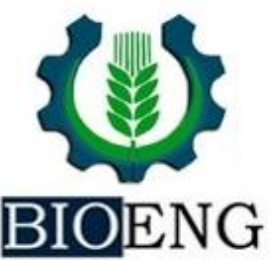

\title{
AVALIAÇÃO DO MODELO DE REGRESSÃO LINEAR MÚLTIPLA E REDES NEURAIS ARTIFICIAIS NA PREVISÃO DO GANHO DE MASSA EM ANIMAIS
}

\section{BIOENG}

\author{
M. L. M. Lopes, F. R. Chavarette ${ }^{*}$, A. M. Cossi
}

UNESP - Univ. Estadual Paulista, Faculdade de Engenharia de Ilha Solteira, Departamento Matemática, Ilha Solteira, SP, Brasil

Article history: Received 10 November 2016; Received in revised form 05 February 2017; Accepted 08 February 2017; Available online 27 March 2017.

\section{RESUMO}

A massa de um animal torna-se uma variável importante a ser estudada, visto que a partir dela, pode-se avaliar o crescimento e o estado nutricional do animal, administrar adequadamente remédios e parasiticidas e estabelecer o valor de venda do animal no mercado. $\mathrm{O}$ artigo aborda o desenvolvimento de uma proposta para previsão do ganho de massa em animais através do método de regressão linear múltipla e de uma técnica baseada na inteligência artificial, mais especificamente, as redes neurais artificiais. $O$ objetivo é desenvolver os dois métodos e aplicá-los na análise de ganho de massa, para isto, levou-se em consideração dados de massa adquiridos pelo animal e o valor de escore de condição corporal obtidos em um determinado período. A análise foi feita utilizando dados de 12 animais avaliados em três períodos distintos e considerando três tipos de alimentação: 1 - alimentação convencional (controle), 2 - caroço de algodão e 3 - farelo de algodão e milho-triturado. Através dos resultados obtidos das análises do erro percentual médio absoluto e do coeficiente de determinação pode-se observar que ambos os métodos demonstram eficiência na previsão de ganho de massa em animais.

Palavras-chave: Estimação do Ganho de Peso. Modelo Estatístico. Perceptron Multicamadas. Algoritmo Backpropagation

\section{AVALIATON OF GAIN WEIGHT ON ANIMALS THROUGH MULTIPLE LINEAR REGRESSION AND ARTIFICIAL NEURAL NETWORKS}

\begin{abstract}
The weight of an animal becomes an important variable to be studied, from it, we evaluated the growth and nutritional status of the animal, administer drugs and parasiticides and establish the sales value of the animal market. In this paper we approach the development of a proposal for the prediction gain weight in animals by the method of multiple linear regression and a technique based on artificial intelligence, more specifically artificial neural networks. The goal is to develop both methods and apply them in the analysis of weight gain, for this, we took into consideration data acquired by the animal weights and the value of body condition score obtained in a given period. The analysis was performed using data from 12
\end{abstract}

\footnotetext{
*abioch@mat.feis.unesp.br
} 
animals evaluated in three different periods and considering three types of feed: 1conventional feed (control), 2 - cottonseed and 3 - cottonseed meal and corn-ground. By means of the results of the analysis of the absolute mean percentage error and the coefficient of determination, it can be observed that both methods demonstrate efficiency in the prediction of mass gain in animals

Keywords: Weight Gain Estimation. Statistical Model. Multilayer Perceptron. Backpropagation Algorithm.

\section{INTRODUÇÃO}

Segundo Festing (2010) os principais motivos de se determinar a massa de um animal podem ser reduzidos à necessidade da utilização dessa variável em alguns estudos. Dentre elas tem-se: avaliação da taxa de crescimento do animal; determinação do seu valor no mercado; seleção de geração de raças; cálculos da dosagem de medicamentos e obtenção de uma relação da saúde geral do animal.

Usualmente, na literatura existem técnicas que são utilizadas para prever ganho de massa de animais e dentre elas podem-se destacar os modelos estatísticos, como por exemplo, regressão linear, que pode ser simples ou múltipla dependendo da quantidade de variáveis envolvidas no problema (ASSIS, 2013; NGO et al., 2013; SANGUN et al., 2009), no qual, pode-se obter uma relação matemática que permita estimar o desempenho do animal com relação às variáveis independentes utilizadas em sua modelagem (ASSIS, 2013).

$\mathrm{Na}$ literatura vem se destacando o uso de sistemas inteligentes e dentre eles destacam-se as redes neurais artificiais (RNAs) (SILVA et al., 2010). As RNAs são concepções fundamentadas no mecanismo do cérebro, sendo, por conseguinte, capazes de aprender com a experiência (SILVA et al., 2010) e constituem-se em uma excelente alternativa para a obtenção de soluções de problemas de um grande número de áreas do conhecimento humano (engenharia, biologia, economia, medicina, etc.), tais como: reconhecimento de padrão, análise, previsão, identificação, controle, etc. A grande vantagem do uso desta tecnologia refere-se à modelagem de problemas complexos, a qual é determinada pelo mecanismo de treinamento (aprendizado) supervisionado (estímulo entrada/saída) ou não supervisionado (baseado somente em estímulos de entrada), ou seja, uma vez concluído o treinamento, a rede armazena, em sua estrutura, o modelo do problema abordado, a princípio, não importando quanto complexo ele é (HAYKIN, 2008).

A proposta deste trabalho foi efetuar o estudo do ganho de massa em animais utilizando Regressão Linear Múltipla (RLM) e Redes Neurais Artificiais (RNAs), mais especificamente, a rede neural artificial Perceptron Multicamadas (MLP) com algoritmo Backpropagation (WIDROW AND LEHR, 1990) e, posteriormente, comparar os resultados obtidos pelos dois métodos.

Para desenvolver os métodos propostos foram levadas em consideração como variáveis independentes na análise: a variação de massa que o animal ganhou em 1 mês (02/09/2009 a 02/10/2009) e a variação de massa que o animal ganhou em 1 mês e 28 dias (02/09/2009 a 30/10/2009). A variável dependente representa o ganho de massa do animal em 9 meses e 17 dias, ou seja, quanto de massa o animal ganhou entre os dias 02/09/2009 a 19/05/2010 (ao final do experimento).

Os resultados obtidos são comparados com os valores reais de ganho de massa de cada animal e, então, é analisado o erro percentual médio (MAPE) e o coeficiente de determinação que indica o quanto a curva de ganho de massa prevista está próxima da curva de ganho de massa real. Esta análise se torna 
importante, ao passo que, através da análise do ganho de massa pode-se estimar o quanto de ração deve ser fornecida ao animal para que ele obtenha este ganho de massa em um determinado período de tempo.

Portanto, a análise comparativa fundamenta que as redes neurais artificiais podem realizar a previsão de ganho de

\section{MATERIAL E MÉTODO}

Os dados coletados foram obtidos de experimento realizado na UNESP de Ilha Solteira (Zootecnia) em 2009. Os animais usados no experimento foram bovinos o qual foram divididos em grupos e cada grupo foi nutrido por uma ração diferente: ração convencional, caroço de algodão e farelo de algodão e milho triturado. Os animais foram pesados em quatro dias distintos, sendo que, para cada dia de pesagem foram obtidos do experimento: 0 peso (massa) dos animais, expressos em $\mathrm{kg}$, e o índice de escore de condição corporal (ECC) (FERNANDES et al., 2012). massa sem a necessidade da análise dos dados (correlação, autocorrelação, etc.) e sem a determinação de um modelo matemático, o que normalmente, é realizado através dos métodos estatísticos. Desta forma, tem-se um procedimento alternativo que irá auxiliar na análise de forma simples e precisa.

O escore de condição corporal (ECC) é uma medida subjetiva baseada na classificação dos animais em função da cobertura muscular e da massa de gordura, desta forma, ele estima o estado nutricional dos animais por meio de avaliação visual e/ou tátil (palpação) realizado por um profissional da área (MACHADO et al., 2008). Existem diferentes escalas de escores, as quais variam no conceito, na topologia dos pontos de observação e na espécie animal à qual são aplicados. Neste trabalho, a escala utilizada foi a escala modificada por Spitzer (SPITZER, 1986), com aplicação de valores de 1 a 9 como mostra a Tabela 1. 
Tabela 1. Escore de condição corporal (SPITZER, 1986)

\begin{tabular}{|c|c|c|}
\hline $\mathrm{ECC}$ & Condição & Características \\
\hline 1 & Debilitada & $\begin{array}{l}\text { A vaca está extremamente magra, sem nenhuma gordura detectável } \\
\text { sobre os processos vertebrais espinhosos e os processos transversos, e } \\
\text { sobre os ossos da bacia e as costelas. A inserção da cauda e as costelas } \\
\text { estão bastante proeminentes. }\end{array}$ \\
\hline 2 & Pobre & $\begin{array}{l}\text { A vaca ainda está muito magra, mas a inserção da cauda e as costelas } \\
\text { estão menos projetadas. Os processos espinhosos continuam } \\
\text { proeminentes, mas nota-se alguma cobertura de tecido sobre a coluna } \\
\text { vertebral. }\end{array}$ \\
\hline 3 & Magra & $\begin{array}{l}\text { As costelas ainda estão individualmente perceptíveis, mas não tão } \\
\text { agudas ao toque. Existe gordura palpável sobre a espinha, sobre a } \\
\text { inserção da cauda e alguma cobertura sobre os ossos da bacia. }\end{array}$ \\
\hline 4 & Limite & $\begin{array}{l}\text { A individualização das costelas é menos óbvia. Os processos } \\
\text { espinhosos podem ser identificados com o toque, mas percebe-se que } \\
\text { estão mais arredondados. Existe um pouco de gordura sobre as } \\
\text { costelas, sobre os processos transversos e sobre os ossos da bacia. }\end{array}$ \\
\hline 5 & Moderada & $\begin{array}{l}\text { O animal possui boa aparência geral. A gordura sobre as costelas } \\
\text { parece esponjosa à palpação e as áreas nos dois lados da inserção da } \\
\text { cauda apresentam gordura palpável. }\end{array}$ \\
\hline 6 & Moderada boa & $\begin{array}{l}\text { É preciso aplicar pressão firme sobre a espinha para sentir os processos } \\
\text { espinhosos. Há bastante gordura palpável sobre as costelas e ao redor } \\
\text { da inserção da cauda. }\end{array}$ \\
\hline 7 & Boa & $\begin{array}{l}\text { A vaca tem aparência gorda e claramente carrega grande quantidade de } \\
\text { gordura. Sobre as costelas sente-se uma cobertura esponjosa evidente e } \\
\text { também ao redor da inserção da cauda. Começam a aparecer "cintos" e } \\
\text { "bolas" de gordura. Notase alguma gordura ao redor da vulva e na } \\
\text { virilha. }\end{array}$ \\
\hline 8 & Gorda & $\begin{array}{l}\text { A vaca está muito gorda. É quase impossível palpar os processos } \\
\text { espinhosos. O animal possui grandes depósitos de gordura sobre as } \\
\text { costelas, na inserção de cauda e abaixo da vulva. Os "cintos" e as } \\
\text { "bolas" de gordura são evidentes. }\end{array}$ \\
\hline 9 & $\begin{array}{l}\text { Extremamente } \\
\text { Gorda }\end{array}$ & $\begin{array}{l}\text { A vaca está nitidamente obesa, com a aparência de um bloco. Os } \\
\text { "cintos" e as "bolas" de gordura estão projetados. A estrutura óssea não } \\
\text { está muito aparente e é difícil de senti-la. A mobilidade do animal está } \\
\text { comprometida pelo excesso de gordura. }\end{array}$ \\
\hline
\end{tabular}

Os valores da escala são definidos de acordo com a quantidade de reservas teciduais, especialmente de gordura e de músculos, em determinadas regiões do corpo, frequentemente associadas a marcos anatômicos específicos, como por exemplo, costelas, processos espinhosos da coluna vertebral, processos transversos da coluna vertebral, etc..
A análise do ganho de massa foi realizada em 36 bovinos o qual foram subdivididos em três grupos. A escolha do animal foi realizada aleatoriamente e desta forma cada grupo era composto por 12 animais. Cada grupo foi tratado com uma ração diferente, ou seja,

- Grupo 1 - ração convencional controle; 
- Grupo 2 - caroço de algodão - CA;

- Grupo 3 - farelo de algodão e milho triturado - FA.

Foram feitas quatro pesagens dos bovinos, sendo a primeira realizada no início do experimento e as três demais pesagens como descrito:

\section{Início do experimento - Primeira} pesagem: 02/09/2009 - $\mathrm{P} 1$;

2. Segunda pesagem: $02 / 10 / 2009-\mathrm{P} 2$;

3. Terceira pesagem: $30 / 10 / 2009$ - P3;

\section{Final do experimento - Quarta pesagem: 19/05/2010 - P4.}

Os dados utilizados para análise do ganho de peso obtidos do experimento estão ilustrados nas Tabelas 2, 3 e 4, respectivamente. A Tabela 2 mostra a massa e o índice de escore de condição corporal (ECC) obtido cada bovino nos respectivos períodos de pesagem, para os animais que pertencem ao grupo 1 , ou seja, que foram tratados com a ração convencional (grupo controle).

Tabela 2. Massa do animal e escore de condição corporal obtidas do experimento - controle

\begin{tabular}{c|c|c|c|c|c|c|c|c}
\hline \multirow{2}{*}{ Animal } & \multicolumn{7}{c}{ Períodos } \\
\cline { 2 - 9 } & \multicolumn{2}{|c|}{ P1 } & \multicolumn{2}{c}{ P2 } & \multicolumn{2}{c}{ P3 } & \multicolumn{2}{c}{ P4 } \\
\cline { 2 - 9 } & $\begin{array}{c}\text { massa } \\
\text { (kg) }\end{array}$ & ECC & $\begin{array}{c}\text { massa } \\
(\mathrm{kg})\end{array}$ & ECC & $\begin{array}{c}\text { massa } \\
(\mathrm{kg})\end{array}$ & ECC & $\begin{array}{c}\text { massa } \\
(\mathrm{kg})\end{array}$ & ECC \\
\hline 1 & 429,0 & 6 & 430,0 & 5 & 423,5 & 5 & 485,0 & 7 \\
\hline 2 & 378,0 & 4 & 380,0 & 4 & 380,0 & 4 & 502,0 & 8 \\
\hline 3 & 431,0 & 7 & 437,0 & 7 & 410,0 & 7 & 462,0 & 8 \\
\hline 4 & 366,0 & 6 & 375,0 & 5 & 360,0 & 5 & 431,0 & 6 \\
\hline 5 & 382,0 & 4 & 377,0 & 3 & 369,0 & 3 & 500,0 & 8 \\
\hline 6 & 461,0 & 5 & 410,0 & 4 & 383,0 & 3 & 501,0 & 7 \\
\hline 7 & 406,0 & 5 & 418,0 & 5 & 412,5 & 5 & 502,0 & 7 \\
\hline 8 & 492,0 & 6 & 473,0 & 5 & 478,0 & 5 & 590,0 & 9 \\
\hline 9 & 412,0 & 5 & 411,0 & 5 & 397,0 & 4 & 502,0 & 8 \\
\hline 10 & 398,0 & 5 & 403,0 & 5 & 391,5 & 4 & 468,0 & 7 \\
\hline 11 & 406,0 & 6 & 410,0 & 6 & 399,5 & 5 & 393,0 & 5 \\
\hline 12 & 250,0 & 3 & 267,0 & 3 & 255,0 & 2 & 486,0 & 8 \\
\hline ECC - Escore de Condição Corporal. &
\end{tabular}

É possível observar na Tabela 3 o valor de massa e o índice de escore de condição corporal (ECC) para cada bovino nos diferentes períodos de pesagem. É importante ressaltar que os animais que participaram deste grupo são distintos dos animais que estão descritos na Tabela 2. Estes animais pertencem ao grupo 2 no qual tem a condição imposta de serem alimentados com caroço de algodão (CA). 
Tabela 3. Massa do animal e escore de condição corporal obtidas do experimento - CA

\begin{tabular}{c|c|c|c|c|c|c|c|c}
\hline \multirow{2}{*}{ Animal } & \multicolumn{7}{|c|}{ Períodos } & \multicolumn{2}{c}{ P3 } & \multicolumn{2}{c}{ P4 } \\
\cline { 2 - 9 } & \multicolumn{2}{|c|}{ P1 } & \multicolumn{2}{c}{ P2 } & \multicolumn{2}{c}{ massa } \\
\cline { 2 - 9 } & mg) & ECC & $\begin{array}{c}\text { massa } \\
(\mathrm{kg})\end{array}$ & ECC & $\begin{array}{c}\text { massa } \\
(\mathrm{kg})\end{array}$ & ECC & $\begin{array}{c}\text { massa } \\
(\mathrm{kg})\end{array}$ & ECC \\
\hline 13 & 397,0 & 5 & 442,0 & 6 & 461,0 & 7 & 493,0 & 8 \\
\hline 14 & 352,0 & 5 & 370,0 & 5 & 380,0 & 5 & 387,0 & 5 \\
\hline 15 & 410,0 & 7 & 485,0 & 7 & 504,0 & 8 & 540,0 & 9 \\
\hline 16 & 367,0 & 4 & 408,0 & 5 & 430,0 & 6 & 438,0 & 6 \\
\hline 17 & 389,0 & 5 & 440,0 & 6 & 470,0 & 7 & 521,0 & 9 \\
\hline 18 & 378,0 & 6 & 407,0 & 5 & 437,0 & 6 & 497,0 & 7 \\
\hline 19 & 440,0 & 7 & 481,0 & 8 & 487,0 & 8 & 484,0 & 8 \\
\hline 20 & 423,0 & 6 & 465,0 & 7 & 488,0 & 7 & 502,0 & 8 \\
\hline 21 & 407,0 & 6 & 453,0 & 6 & 427,0 & 6 & 484,0 & 7 \\
\hline 22 & 348,0 & 5 & 397,0 & 5 & 324,0 & 4 & 388,0 & 5 \\
\hline 23 & 269,0 & 3 & 380,0 & 6 & 500,0 & 8 & 492,0 & 8 \\
\hline 24 & 328,0 & 5 & 299,0 & 2 & 410,0 & 6 & 415,0 & 6 \\
\hline
\end{tabular}

ECC - Escore de Condição Corporal.

A Tabela 4 apresenta o valor de massa e o índice de escore de condição corporal (ECC) para cada bovino nos períodos $\mathrm{P} 1, \mathrm{P} 2$, P3 e P4, respectivamente. Os animais que participaram deste grupo são dessemelhante dos animais que estão descritos nas Tabelas 2 e 3, respectivamente. Estes animais pertencem ao grupo 3 no qual tem a condição imposta de serem alimentados com farelo de algodão e milho triturado (FA).

Tabela 4. Massa do animal e escore de condição corporal obtidas do experimento - FA

\begin{tabular}{|c|c|c|c|c|c|c|c|c|}
\hline \multirow{3}{*}{ Animal } & \multicolumn{8}{|c|}{ Períodos } \\
\hline & \multicolumn{2}{|c|}{$\mathrm{P} 1$} & \multicolumn{2}{|c|}{$\mathrm{P} 2$} & \multicolumn{2}{|c|}{ P3 } & \multicolumn{2}{|c|}{$\mathrm{P} 4$} \\
\hline & $\begin{array}{c}\text { massa } \\
(\mathrm{kg})\end{array}$ & ECC & $\begin{array}{c}\text { massa } \\
(\mathrm{kg})\end{array}$ & ECC & $\begin{array}{c}\text { massa } \\
(\mathrm{kg})\end{array}$ & ECC & $\begin{array}{c}\text { massa } \\
(\mathrm{kg})\end{array}$ & ECC \\
\hline 25 & 431,0 & 6 & 461,0 & 7 & 481,5 & 7 & 442,0 & 7 \\
\hline 26 & 399,0 & 5 & 416,0 & 5 & 434,0 & 6 & 446,0 & 7 \\
\hline 27 & 468,0 & 7 & 478,0 & 7 & 501,5 & 8 & 488,0 & 7 \\
\hline 28 & 463,0 & 6 & 465,0 & 6 & 501,0 & 7 & 522,0 & 8 \\
\hline 29 & 433,0 & 5 & 462,0 & 6 & 527,5 & 7 & 546,0 & 9 \\
\hline 30 & 428,0 & 6 & 449,0 & 6 & 478,5 & 6 & 529,0 & 8 \\
\hline 31 & 367,0 & 4 & 400,0 & 4 & 436,0 & 6 & 474,0 & 6 \\
\hline 32 & 370,0 & 5 & 353,0 & 4 & 458,0 & 4 & 439,0 & 6 \\
\hline 33 & 366,0 & 4 & 360,0 & 4 & 374,5 & 4 & 462,0 & 7 \\
\hline 34 & 330,0 & 3 & 335,0 & 3 & 326,0 & 3 & 448,0 & 6 \\
\hline 35 & 360,0 & 5 & 379,0 & 5 & 383,5 & 6 & 409,0 & 7 \\
\hline 36 & 419,0 & 6 & 403,0 & 6 & 406,0 & 6 & 467,0 & 8 \\
\hline
\end{tabular}

ECC - Escore de Condição Corporal.

Os métodos utilizados na análise do ganho de massa em animais são: Redes
Neurais Artificiais e Regressão Linear Múltipla. Cada método será devidamente 
apresentado, bem como, as estratégias utilizadas pelos métodos para efetuar a

\section{Redes Neurais Artificiais}

As redes neurais artificiais são técnicas computacionais que apresentam um modelo matemático inspirado na estrutura neural de organismos inteligentes

$$
s_{i}=\sum_{j}^{n} w_{i j} x_{j}
$$

em que:

$s_{i} \quad$ - saída linear do neurônio $i$;

$x_{j} \quad$ - entradas do neurônio; (neurônios) e que adquirem conhecimento através da experiência. A saída de um neurônio artificial é, então, dada pela Equação (1) (SILVA et al., 2010)

$$
v_{i}=\frac{1-e^{-\lambda s_{i}}}{1+e^{-\lambda s_{i}}}
$$

no qual:

$y_{i} \quad$ - $\quad$ saída não linear do neurônio $i$;

$\lambda$ - constante que determina a inclinação da função sigmóide.

A rede neural artificial utilizada foi a Perceptron Multicamadas (MLP) com algoritmo de treinamento Backpropagation (WIDROW AND LEHR, 1990). Este algoritmo possui um procedimento sistemático de adaptação de massa baseado no método do gradiente descendente, de forma que, o erro quadrático da rede neural seja minimizado.

Considerando-se o neurônio de índice $i$ da rede, e utilizando-se o método do gradiente descendente (WIDROW AND LEHR, 1990), o ajuste de massa é formulado pela Equação (3):

$$
V_{i}(k+1)=V_{i}(k)+2 \gamma \beta_{i} X_{i}
$$

em que:

$\gamma \quad$ - parâmetro de controle da estabilidade ou taxa de treinamento;

$X_{i} \quad$ - vetor contendo as entradas do neurônio $i$;
$V_{i} \quad$ - vetor contendo os pesos do neurônio $i$;

$$
=\left[\begin{array}{lllll}
w_{0 i} & w_{1 i} & w_{2 i} & \ldots & w_{n i}
\end{array}\right]^{\mathrm{T}} .
$$

A Equação (4) descreve $\beta_{i}$ quando o elemento $i$ encontra-se na última camada, então

$$
\beta_{i}=\operatorname{sgm}^{\prime}\left(s_{i}\right) \varepsilon_{i}
$$

no qual:

$\operatorname{sgm}^{\prime}\left(s_{i}\right)-\quad$ derivada da função

sigmóide com relação a $s_{i}$;

$\varepsilon_{i}=d_{i}-y_{i}$; $d_{i}$ - saída desejada do neurônio $i$.

Se o elemento $i$ encontrar-se nas demais camadas, $\beta_{i}$ é determinado pela Equação (5): 


$$
\beta_{i}=\operatorname{sgm}^{\prime}\left(s_{i}\right) \sum_{k \in R(j)} w_{i k} \beta_{k}
$$

no qual:

$$
\operatorname{sgm}^{\prime}\left(s_{i}\right) \text { - derivada da função }
$$

sigmóide com relação a $s_{i}$.

$R(j) \quad$ - conjunto dos índices dos elementos que se encontram na fileira seguinte à fileira do elemento $i$ e que estão interligados ao elemento $i$.

\section{Previsão do ganho de massa utilizando} rede neural artificial
A rede neural Perceptron

Multicamadas com algoritmo

Backpropagation foi usada para realizar a previsão do ganho de massa em bovinos submetidos a três tipos de alimentação. Para compor o conjunto de dados de entrada da rede neural foram utilizados os valores de massa dos animais e o escore de condição corporal (ECC) analisados em um determinado período de tempo.

O conjunto de dados de entrada da rede neural MLP via Backpropagation contêm dados que compreendem dois

$$
\begin{aligned}
& \boldsymbol{X}(h)=\left[\begin{array}{lll}
\mathrm{P}_{n}(i) & \mathrm{P}_{n}(i+h) & \mathrm{G}_{E C C}
\end{array}\right]^{\mathrm{T}}, \\
& \boldsymbol{Y}(h)=\left[\begin{array}{ll}
\mathrm{GP}_{n}
\end{array}\right]
\end{aligned}
$$

em que:

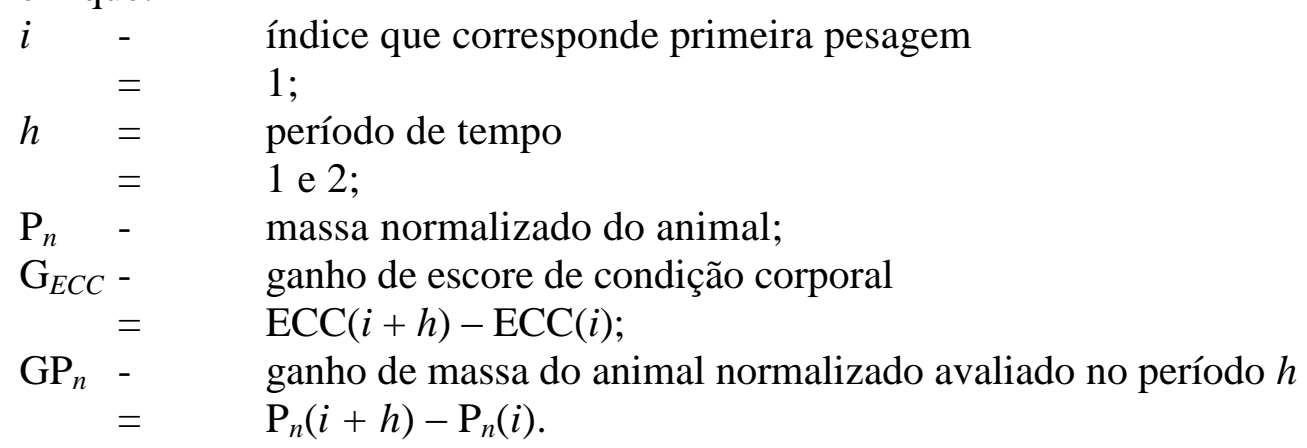

Observa-se que o vetor $\boldsymbol{X}(1)$ referese às informações do $1^{\circ}$ período e o vetor $\boldsymbol{X}(2)$ refere-se ao $2^{\underline{o}}$ período. Portanto, tem-se que o conjunto de dados de entrada da rede neural para a fase de treinamento contempla informações dos dois períodos distintos, $\boldsymbol{X}(1)$ e $\boldsymbol{X}(2)$, sendo que em cada período a análise foi efetuada levando em consideração a massa de 12 bovinos. Desta forma, a quantidade de dados que serão utilizados na fase de treinamento da rede neural contém um total de 24 informações (12 dados referentes ao primeiro período e 12 dados relacionados ao segundo período). O conjunto de dados de saída da rede neural para fase de treinamento é representado pelos vetores: $\boldsymbol{Y}(1)$ que é a saída correspondente ao vetor $\boldsymbol{X}(1)$ e $\boldsymbol{Y}(2)$ que é a saída referente ao vetor $\boldsymbol{X}(2)$. Ambos os vetores de saída, $\boldsymbol{Y}(1)$ e $\boldsymbol{Y}(2)$, representam o quanto $\mathrm{o}$ 
animal terá de ganho de massa nos $1^{\underline{0}}$ e $2^{\underline{o}}$ períodos, respectivamente.

$O$ vetor $\boldsymbol{X}(3)$ pertence ao conjunto de dados de entrada da rede neural na fase de diagnóstico da rede neural e este é caracterizado pelo conjunto de dados que contêm a variação de peso dos animais do início até o final do experimento, o qual corresponde ao $3^{\underline{0}}$ período. Consequentemente, o vetor $\boldsymbol{Y}(3)$ será o conjunto de dados de saída a ser previsto, ou seja, o ganho de massa do animal.

\section{Regressão Linear Múltipla}

O método de regressão linear, simples ou múltipla, obtém uma reta ou curva que se aproxima melhor dos dados que são fortemente correlacionados. Como as variáveis independentes associadas ao problema do ganho de massa são: massa do animal, no início e

$$
\hat{y}=m_{1} x_{1}+m_{2} x_{2}+\cdots+m_{v} x_{v}+b
$$

no qual, $x_{1}, x_{2}, \ldots, x_{v}$, são variáveis independentes, $b$ é a interseção com a variável dependente $y$. Os coeficientes $m_{1}$, $m_{2}, \ldots, m_{v}$ são estimados através do método dos mínimos quadrados.

Previsão do ganho de massa utilizando regressão linear múltipla

Os dados utilizados no cálculo da equação de regressão linear múltipla foram idênticos ao utilizado pela rede

$$
\begin{aligned}
& \bullet x_{1}=\mathrm{P}_{n}(i) \\
& \bullet x_{2}=\mathrm{P}_{n}(i+h) \\
& \bullet x_{3}=\mathrm{G}_{E C C} \\
& \bullet y=f\left(x_{1}, x_{2}, x_{3}\right)=\mathrm{GP}_{n}
\end{aligned}
$$

para $h=1,2$ e 3, e portanto, tem-se a equação de regressão dada pela Equação (15)

$$
\hat{y}=m_{1} x_{1}+m_{2} x_{2}+m_{3} x_{3}+b
$$

no qual os coeficientes $m_{1}, m_{2}$ e $m_{3}$ serão determinados através do método dos cedidas a rede neural pelos dados de entrada, ela terá a capacidade de generalizar o ganho de massa do animal para um determinado período de tempo (período este que não está presente no conjunto de dados de entrada da rede neural) utilizando períodos anteriores a este. A rede neural MLP com algoritmo Backpropagation foi programada em Fortran.

fim do período, e escore de condição corporal, a equação de regressão linear que melhor irá se ajustar a este conjunto de dados é a regressão linear múltipla (ASSIS, 2013).

Uma equação de regressão linear múltipla é dada pela Equação (10):

neural artificial. Logo, para obter a curva de regressão foram adotados: a massa do animal no início do período, a massa do animal no fim do período e o ganho de escore de condição corporal, Equação (8), e estão denotados pelas Equações (11), (12) e (13), respectivamente, e a variável dependente que corresponde ao ganho de massa do animal, Equação (9), está representado na Equação (14): 
de dados (controle, caroço de algodão e

farelo de algodão com milho triturado).

\section{Critérios para análise da previsão do ganho de massa}

Para uma análise da precisão do ganho de massa previsto, são definidos o erro percentual absoluto médio $(M A P E)$ e o coeficiente de determinação $R^{2}$, respectivamente, pelas Equações (16) e (17).

$$
\begin{aligned}
& \text { MAPE }=\frac{1}{N}\left\{\sum_{i=1}^{N}\left(\left|\mathrm{GP}_{\text {real }}-\mathrm{GP}_{M L P}\right|\right) / \mathrm{GP}_{\text {real }}\right\} \times 100 \\
& R^{2}=\sum_{i=1}^{N}\left(\mathrm{GP}_{M L P}-\mathrm{GP}_{\text {médio }}\right)^{2} / \sum_{i=1}^{N}\left(\mathrm{GP}_{\text {real }}-\mathrm{GP}_{\text {médio }}\right)^{2}
\end{aligned}
$$

em que:

$G P_{\text {real }}$ - ganho de massa real do animal avaliado no terceiro período;

$G P_{\text {médio }}$ - média do ganho de massa real do animal avaliado no terceiro período;

\section{RESULTADOS E DISCUSSÃO}

Este trabalho realizou a previsão do ganho de massa de um animal utilizando duas metodologias: redes neurais artificiais e regressão linear múltipla.

A primeira técnica utilizada na previsão do ganho de massa em animais (bovinos) foi à rede neural artificial
$G P_{M L P}$ - ganho de massa do animal obtido pela MLP avaliado no terceiro período;

$N \quad$ - número de animais.

Tabela 5. Parâmetros da Rede Neural MLP com Algoritmo Backpropagation

\begin{tabular}{lccc}
\hline \multicolumn{1}{c}{ Parâmetros da Rede } & \multicolumn{3}{c}{ Alimentação } \\
\cline { 2 - 4 }$\quad$ Neural Artificial & Controle & CA & FA \\
\hline Número de dados & 24 & 24 & 24 \\
Número de camadas & 3 & 3 & 3 \\
Número de neurônios por & $3-8-1$ & $3-8-1$ & $3-8-1$ \\
camada & $2 \times 10^{-3}$ & $2 \times 10^{-3}$ & $2 \times 10^{-3}$ \\
Tolerância & 0,5 & 1,5 & 1,5 \\
Taxa de treinamento & 0,9 & 0,9 & 0,9 \\
Termo momento &
\end{tabular}

CA - Caroço de Algodão; FA - Farelo de Algodão e Milho Triturado.

A fase de diagnóstico teve o propósito de estimar o ganho de massa do animal obtido durante todo o experimento, ou seja, do início ao final do experimento. Portanto, a quantidade de dados de entrada da rede neural MLP utilizados na fase de diagnóstico é doze ("12") que corresponde ao total de bovinos usados no experimento (para cada tipo de alimentação). Para validar a metodologia
Perceptron Multicamadas (MLP) com algoritmo Backpropagation. A Tabela 5 apresenta os parâmetros utilizados para o treinamento da rede neural MLP com algoritmo Backpropagation aplicado ao problema de previsão do ganho de massa. 
triturado. No gráfico a barra em azul ilustra o ganho de massa real e a barra vermelha o ganho de massa previsto pela RNA.

Na Figura 1 é possível observar que os valores previstos pela rede neural artificial estão coerentes com os valores de ganho de massa real referente a cada animal analisado, ou seja, 12 bovinos que foram alimentados com a ração convencional.

Ganho de Massa - Real घ Ganho de Massa - RNA

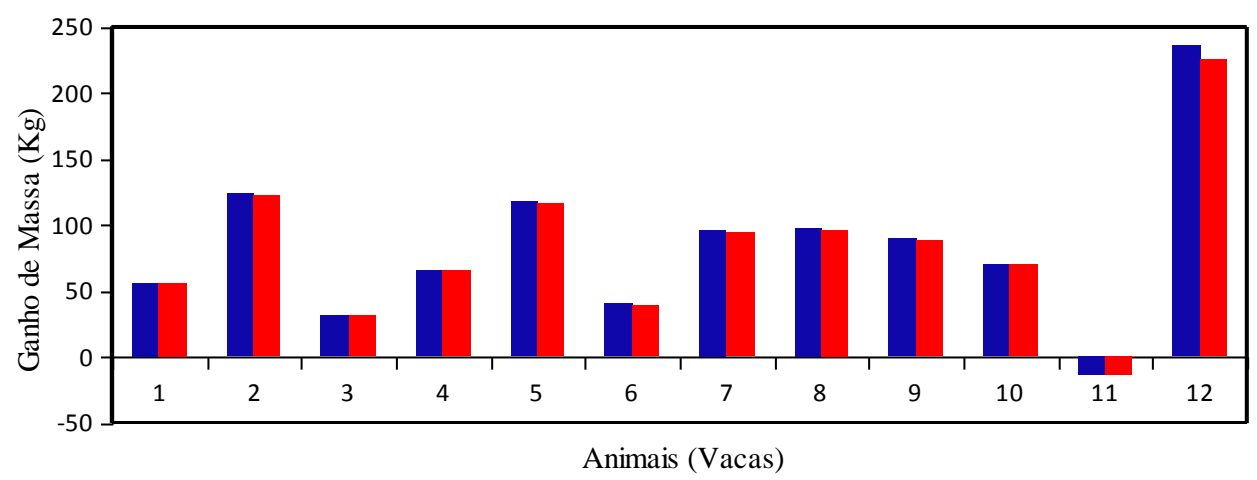

Figura 1. Visualização do ganho de massa real e obtida pela RNA - controle

Para os animais tratados com caroço de algodão, observam-se pela Figura 2 que os valores previstos pela rede neural artificial estão muito próximos dos valores de ganho de massa real.

- Ganho de Massa - Real

Ganho de Massa - RNA

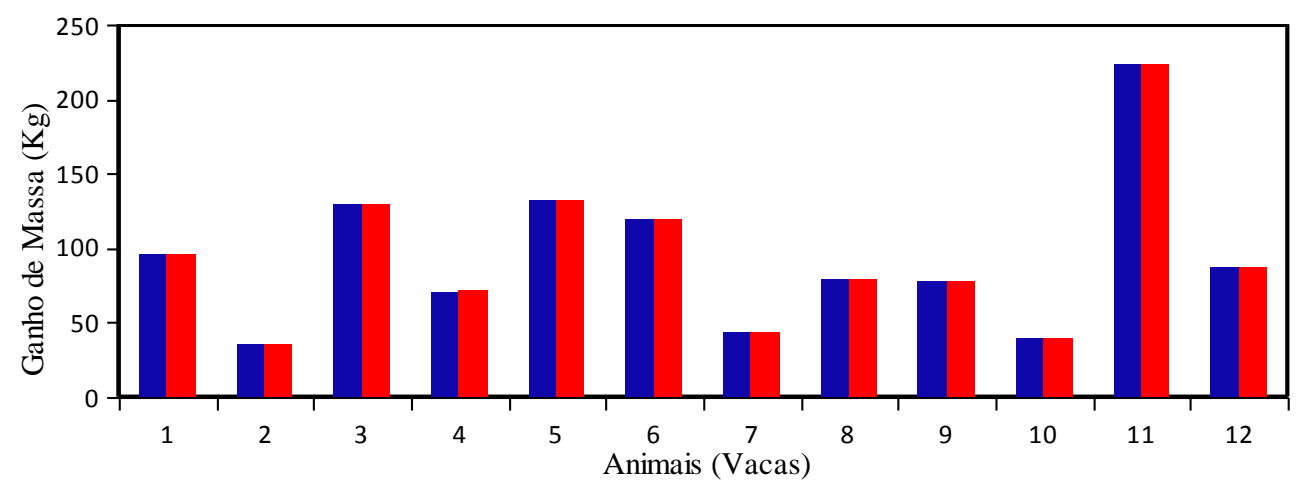

Figura 2. Visualização do ganho de massa real e obtida pela RNA - CA

Na Figura 3 pode-se notar o mesmo comportamento dos resultados obtidos na Figura 2, ou seja, os valores previstos pela rede neural artificial estão bem próximos dos valores de ganho de massa real. Os resultados obtidos foram para os animais tratados com farelo de algodão e milho triturado. 


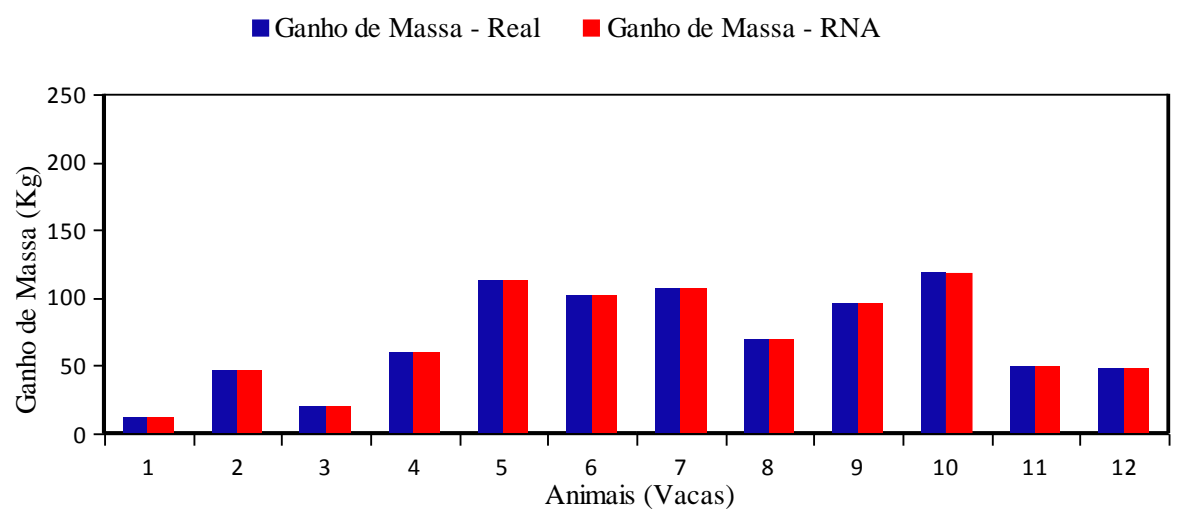

Figura 3. Visualização do ganho de massa real e obtida pela RNA - FA

A segunda técnica usada foi o modelo de regressão linear múltipla sendo que as equações de regressão foram obtidas utilizando os dados correspondentes a massa do animal no início do experimento e no período em análise e o índice de escore de condição corporal.

Levando em consideração os dados referentes à massa do animal no início do experimento e no período em análise $\left(1^{\underline{0}} \mathrm{e}\right.$ $2^{\underline{0}}$ períodos) e o índice de escore de condição corporal têm-se a equação de regressão linear múltipla para o grupo 1 (ração convencional - controle) obtido pelo método dos mínimos quadrados, cujo modelo foi desenvolvido no LibreOffice versão 5.1.6.2, dada pela Equação (18).

$$
\hat{y}=-1,000276 x_{1}+0,999814 x_{2}-0,000016 x_{3}+0,000215
$$

Substituindo os dados das variáveis definidas pelas Equações (11), (12) e (13), referentes ao $3^{0}$ período, na Equação (18) têm-se os valores de ganho de massa ilustrados na Figura 4. Nota-se que os valores de ganho de massa obtidos pela curva de regressão são muito próximos do valor de ganho de massa real.

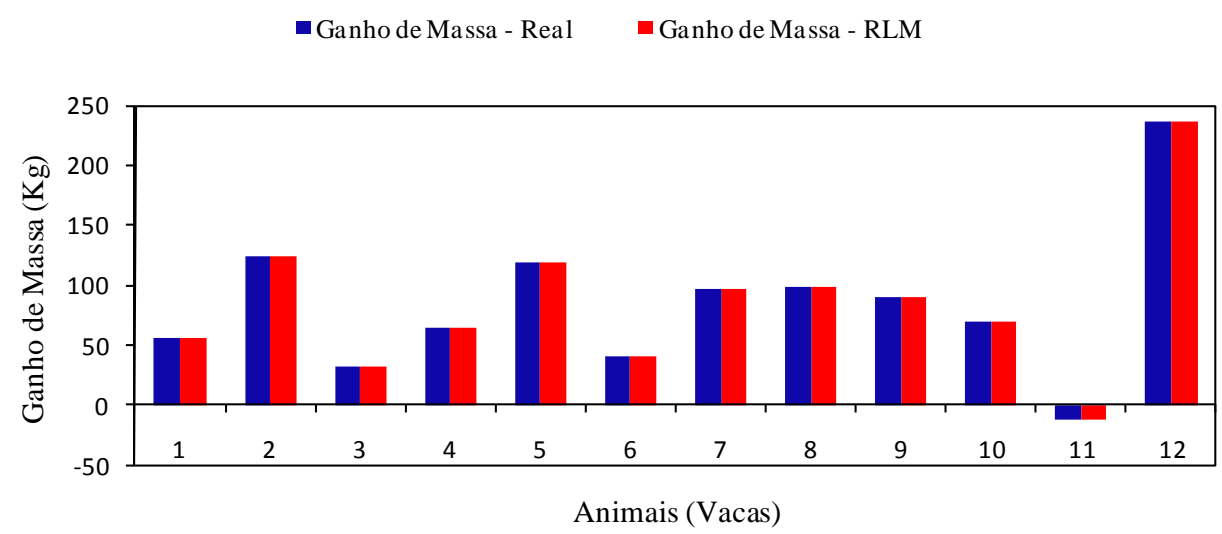

Figura 4. Visualização do ganho de massa real e obtida pela RLM - controle

Para os dados referentes à massa do animal no início do experimento e no período em análise ( $1^{\underline{o}}$ e $2^{\underline{o}}$ períodos) e o índice de escore de condição corporal têm-se para o grupo 2 (caroço de algodão) a equação de regressão linear múltipla definida pela Equação (19). 


$$
\hat{y}=-0,999668 x_{1}+0,999928 x_{2}+0,000011 x_{3}-0,000121
$$

Empregando os dados das variáveis definidas pelas Equações (11), (12) e (13), referentes ao $3^{0}$ período, na Equação (19) é obtido os valores de ganho de massa que pode ser visto na Figura 5 e através desta é possível verificar a proximidade dos valores reais.

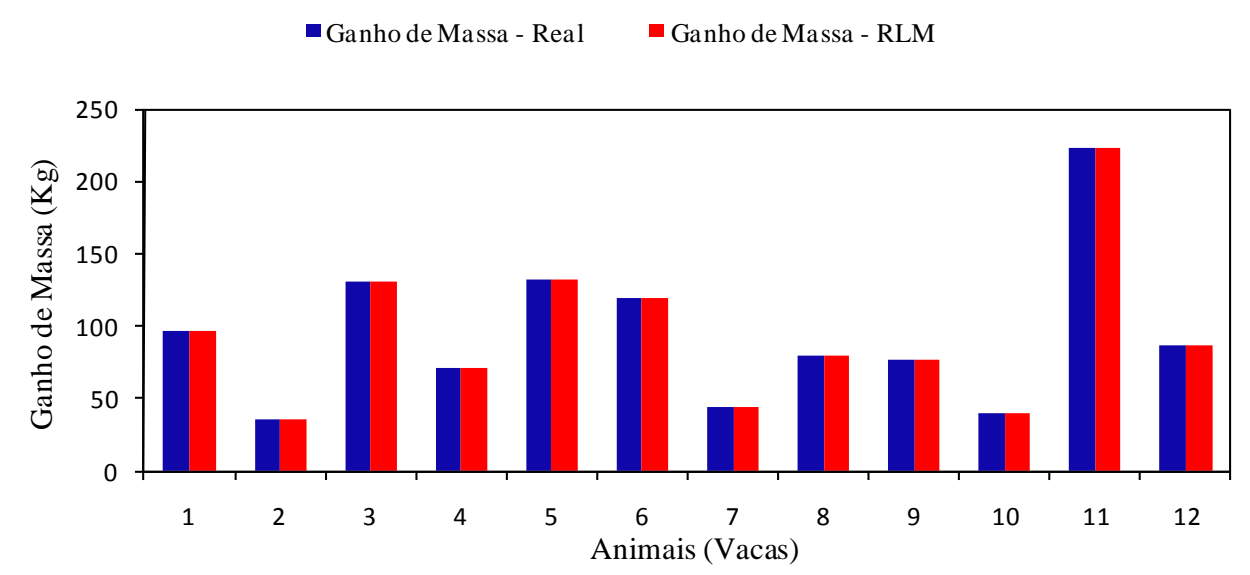

Figura 5. Visualização do ganho de massa real e obtida pela RLM - CA

Utilizando o mesmo procedimento mencionado para os grupos 1 e 2 , tem-se a determinação da equação de regressão linear múltipla correspondente ao grupo 3 (farelo de algodão e milho triturado) dada pela Equação (20).

$$
\hat{y}=-1,000111 x_{1}+0,999972 x_{2}-0,000015 x_{3}+0,000060
$$

As variáveis definidas pelas Equações (11), (12) e (13), referentes ao $3^{0}$ período, usadas na Equação (20) fornece os valores de ganho de massa para o grupo 3 que pode ser visto na Figura 6. Para este grupo constata-se que os valores obtidos da equação de regressão dada pela Equação (20) são muito semelhantes aos valores de ganho de massa real.

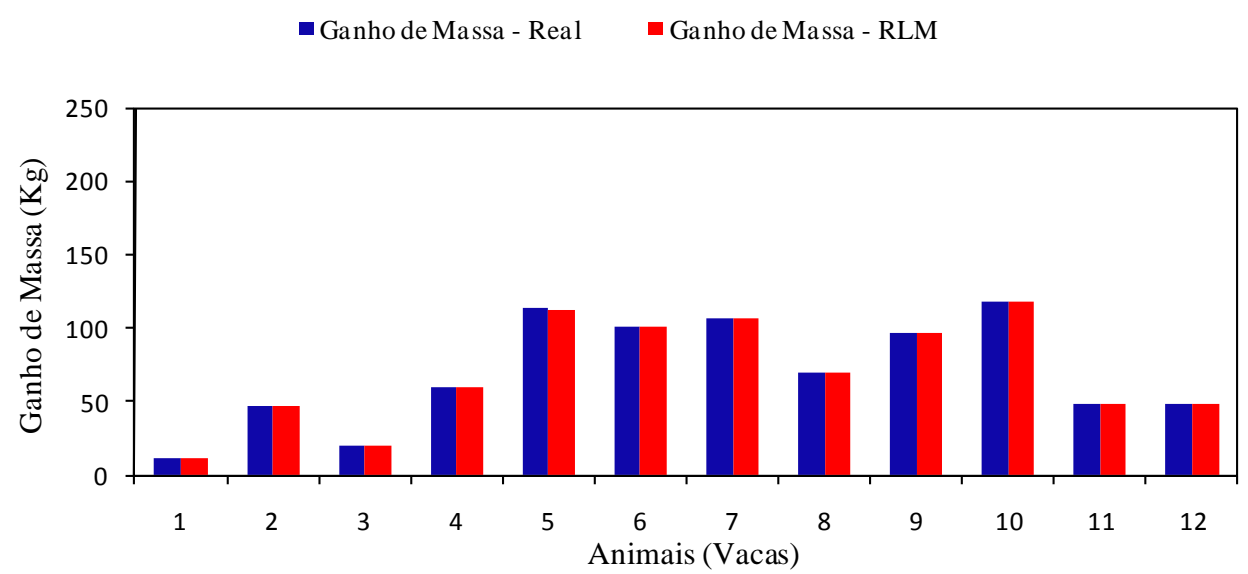

Figura 6. Visualização do ganho de massa real e obtida pela RLM - FA

Pode-se observar nas Figuras 1 e 4 que os ganhos de pesos reais variam entre a perda de massa de $13 \mathrm{~kg}$ a um ganho de massa de 236 kg. Já nas Figuras 2 e 5 as 
variações limitam-se apenas aos ganhos de massa com um ganho mínimo de $35 \mathrm{~kg}$ a um ganho máximo de $223 \mathrm{~kg}$. Através das Figuras 3 e 6, nota-se que os animais alimentados com o farelo de algodão e milho triturado, obtiveram os menores ganhos de massa que variam $11 \mathrm{~kg}$ e 118 $\mathrm{kg}$.

A partir dos resultados mostrados pela Tabela 6, observa-se através do MAPE uma precisão na previsão do ganho de massa dos animais, ou seja, os resultados obtidos pela rede neural Perceptron Multicamadas com algoritmo Backpropagation são aproximadamente idênticos aos ganhos de massa real dos animais com um erro percentual médio, MAPE variando entre $1,4 \%$ a $0,10 \%$. Também, pode-se observar o valor do MAPE obtido pela equação de regressão linear múltipla e estes demonstram uma boa precisão na previsão do ganho de massa dos animais, uma vez que, foi possível observar que estes valores de erros refletem nas Figuras 1 a 6, valores de ganhos previstos muito próximos de valores de ganhos reais. Nota-se que o erro percentual médio, MAPE variando entre $0,04 \%$ a $0,09 \%$.

Tabela 6. Análise comparativa dos ganhos massa real e obtido pelos métodos: RNA e RLM

\begin{tabular}{|c|c|c|c|c|}
\hline \multirow{2}{*}{$\begin{array}{l}\text { Método } \\
\text { Utilizado }\end{array}$} & \multirow{2}{*}{ Avaliação } & \multicolumn{3}{|c|}{ Alimentação } \\
\hline & & Controle & $\mathrm{CA}$ & FA \\
\hline \multirow{2}{*}{ RNA } & $\begin{array}{l}\text { Erro Percentual Médio - } \\
M A P E(\%)\end{array}$ & 1,43 & 0,18 & 0,10 \\
\hline & $\begin{array}{l}\text { Coeficiente de } \\
\text { Determinação - } R^{2}\end{array}$ & 0,92 & 1,00 & 1,00 \\
\hline \multirow{2}{*}{ RLM } & $\begin{array}{l}\text { Erro Percentual Médio - } \\
M A P E(\%)\end{array}$ & 0,07 & 0,04 & 0,09 \\
\hline & $\begin{array}{l}\text { Coeficiente de } \\
\text { Determinação }-R^{2}\end{array}$ & 1,00 & 1,00 & 1,00 \\
\hline
\end{tabular}

RNA - Rede Neural Artificial; RLM - Regressão Linear Múltipla, CA - Caroço de Algodão;

FA - Farelo de Algodão e Milho Triturado. RNA.

A Figura 7 ilustra o ajuste dos valores de ganhos de massa previstos pela RLM e pela

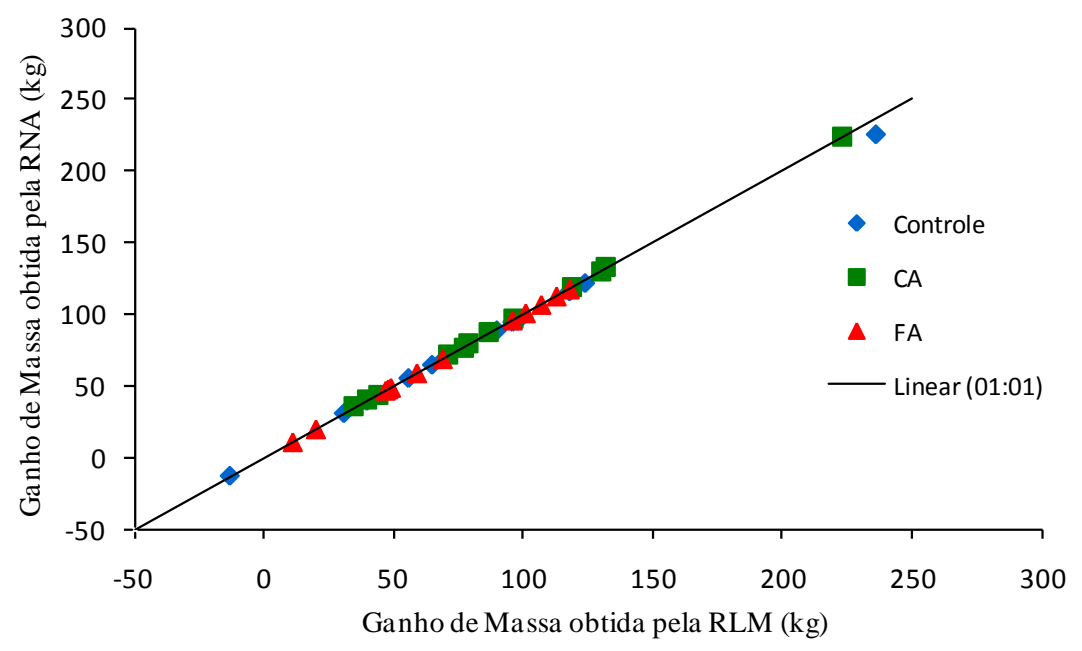

Figura 7. Diagrama de dispersão dos ganhos de massa obtidos pela RLM e pela RNA para as três alimentações (controle, caroço de algodão, farelo de algodão e milho triturado) 
Observa-se na Figura 7 que as previsões realizadas por ambas combinam, ou seja, são muito parecidas.
Isto pode ser evidenciado pelo coeficiente de determinação, $\mathrm{R}^{2}$, mostrado na Tabela 7 .

Tabela 7. Análise comparativa dos valores de ganhos de massa obtidos pela RNA e RLM

\begin{tabular}{lccc}
\hline \multirow{1}{*}{ Avaliação } & \multicolumn{3}{c}{ Alimentação } \\
\cline { 2 - 4 } & $\begin{array}{c}\text { Control } \\
\mathbf{e}\end{array}$ & $\mathbf{C A}$ & FA \\
\hline $\begin{array}{l}\text { Erro Percentual Médio - } \\
M A P E(\%)\end{array}$ & 1,35 & 0,18 & 0,11 \\
$\begin{array}{l}\text { Coeficiente de } \\
\text { Determinação - R }\end{array}$ & 0,92 & 1,00 & 1,00 \\
\hline
\end{tabular}

CA - Caroço de Algodão; FA - Farelo de Algodão e Milho Triturado.

Na Tabela 7 nota-se que os resultados obtidos de ganho de massa com relação ao caroço de algodão e farelo de algodão com milho triturado para os dois métodos (RNA e RLM) foram muito semelhantes, ou seja, ambos os métodos fornecem resultados de previsão parecidos ou muitos próximos. O que não ocorre com relação ao grupo o qual foi alimentado pela ração controle. Esta diferença está associada a um possível erro experimental que pode ser observado na Tabela 8.

Tabela 8. Massa animal para o grupo 1 tratado com a ração convencional

\begin{tabular}{ccccc}
\hline \multirow{2}{*}{ Animal } & \multicolumn{4}{c}{ Massa do animal (Kg) } \\
\cline { 2 - 5 } & $\begin{array}{c}\text { Início do } \\
\text { Experimento }\end{array}$ & $\begin{array}{c}\mathbf{1}^{\mathbf{a}} \\
\text { Pesagem }\end{array}$ & $\begin{array}{c}\mathbf{2}^{\mathbf{a}} \\
\text { Pesagem }\end{array}$ & $\begin{array}{c}\mathbf{3}^{\mathbf{a}} \\
\text { Pesagem }\end{array}$ \\
\hline $8^{8^{\mathbf{a}}}$ & 492 & 473 & 478 & 590 \\
$12^{\mathrm{a}}$ & 250 & 267 & 255 & 486 \\
\hline
\end{tabular}

Nota-se que os animais selecionados (aleatoriamente) para compor o grupo 1, ou seja, o grupo que recebeu a ração convencional possuem uma grande variação de massa, sendo que, entre os 12 bovinos que fazem parte do grupo 1 , notase através da Tabela 2 que o animal mais leve tem a massa inicial de $250 \mathrm{~kg}$ e o animal mais pesado a massa de $492 \mathrm{~kg}$. Nos demais grupos esta diferença entre as massas dos animais (mais leve e mais pesado) é em torno de $28,75 \%$ a menos para o grupo alimentado com caroço de algodão (CA), e por volta de $42,5 \%$ a menos para a alimentação feita por farelo de algodão com milho triturado (FA). Constata-se também, que o animal mais pesado do grupo ao final do experimento tem um ganho de massa de $98 \mathrm{~kg}$ e o animal mais leve do grupo tem um ganho de $236 \mathrm{~kg}$. Esta diferença existente entre os animais enfoca uma variação que não existe com os demais dados dentro do grupo. Portanto, esta diferença acaba interferindo na generalização realizada pela rede neural, uma vez que, esta não irá ocorrer novamente.

Observando os resultados obtidos pela rede neural artificial nota-se que a melhor previsão do ganho de massa foi para o grupo farelo de algodão com milho triturado e esta está associada ao fato do grupo de animais serem mais homogêneo, na qual, a variação da massa foi a menor o possível. Isto representa uma característica imprescindível para o funcionamento de uma rede neural artificial, uma vez que, ela tem a capacidade de generalizar o aprendizado para um determinado comportamento.

Os resultados obtidos demonstram que as duas metodologias propostas são eficientes e precisas, uma vez que, o erro percentual médio, MAPE, varia em torno de $0,10 \%$ a $1,4 \%$ para a previsão feita através da rede neural artificial e em torno 
de $0,04 \%$ a $0,09 \%$ para a previsão realizada pela regressão linear múltipla. Através do coeficiente de determinação, $\mathrm{R}^{2}$, observa-se a garantia de ajuste ou

\section{CONCLUSÕES}

As metodologias propostas para estimar o ganho de massa de peso animal se basearam na regressão linear múltipla e redes neurais artificiais.

$\mathrm{Na}$ utilização dos métodos estatísticos (regressão linear múltipla) deve-se dispor de um modelo estatístico e matemático. Então, a qualidade das soluções depende de uma boa escolha do modelo, baseado, principalmente, na determinação das influências de cada variável adotada no modelo considerado. Esta atividade é bastante complexa e exige, portanto, um grande empreendimento de esforços, conhecimento e habilidade dos profissionais da área. Com os dados coletados do experimento notou-se que o modelo que mais se adequava era o modelo de regressão linear múltipla, e isto se torna evidente, uma vez que, constatamse as variações na massa e no ECC do animal a cada pesagem (P1, P2, P3 e P4). Avaliou-se a correlação existente entre os dados reunidos do experimento, para assim, selecionar as variáveis a serem utilizadas como variáveis independentes no modelo de regressão linear múltipla.

Já as redes neurais artificiais têm se mostrado de forma eficiente no desenvolvimento de séries temporais,

\section{AGRADECIMENTOS}

Os autores agradecem ao suporte financeiro da Fundunesp (Fundação para o Desenvolvimento da UNESP - Processo $n^{\circ}$.

\section{REFERÊNCIAS BIBLIOGRÁFICAS}

ASSIS, J. P. Regressão e Correlação Linear Simples e Múltipla, Editora UFERSA, Mossoró - RN, 2013. precisão da previsão comparada aos ganhos de massa reais para as duas técnicas utilizadas.

principalmente, porque não há necessidade de se conhecer o modelo matemático, ou seja, as correlações entre variáveis são estabelecidas de forma autônoma. A escolha da rede neural Perceptron via algoritmo Backpropagation, deve-se ao fato, desta arquitetura ser considerada na literatura um benchmark em termos de precisão (WIDROW AND LEHR, 1990).

Os resultados obtidos demonstram que as duas metodologias propostas são eficientes e precisas, uma vez que, o erro percentual médio, MAPE, varia em torno de $0,10 \%$ a $1,4 \%$ para a previsão feita através da rede neural artificial e em torno de $0,04 \%$ a $0,09 \%$ para a previsão realizada pela regressão linear múltipla. Através do coeficiente de determinação, $\mathrm{R}^{2}$, observa-se a garantia de ajuste ou precisão da previsão comparada aos ganhos de massa reais para as duas técnicas utilizadas.

Com isso, pode-se concluir que ambas as técnicas utilizadas produziram resultados satisfatórios e muito semelhantes, mesmo tendo abordagens diferentes, sendo assim, ressalta-se que a escolha da estratégia para a obtenção destes resultados dependerá do perfil do profissional.

0051610) e ao Laboratório de Sistemas Complexos (Sisplexos) pelo espaço físico cedido para o desenvolvimento do projeto.

FERNANDES, A. F. A., NEVES, H. H. R.; GUARINI, A. R., OLIVEIRA, J. A., CARVALHEIRO, R., QUEIROZ, S. A. 
Associação de escores de condição corporal de vacas com características reprodutivas e de desempenho de seus bezerros, In: IX SIMPÓSIO BRASILEIRO DE MELHORAMENTO ANIMAL, João Pessoa - PB, p. 1-6, 2012.

FESTING, M. Statistics and Animals in Biomedical Research, Significance, v. 7, n. 4, p. 176-177, 2010.

HAYKIN, S. Neural Networks and Learning Machines, Prentice Hall, Third Edition, 2008.

MACHADO, R., CORRÊA, R. F., BARBOSA, R. T., BERGAMASCHI, M. A. C. M. Escore Da Condição Corporal e sua Aplicação no Manejo Reprodutivo de Ruminantes, São Carlos: Embrapa Pecuária Sudeste, 2008. 16p. (Circular técnica, 57).

MARINI, F. 3.14 -
Reference Module in Networks,
Molecular Sciences and Chemical
Engineering, from Comprehensive
Chemometrics, 2009, v. 3, p. 477-505,
Current as of 20 April 2013.

NGO, T. H. D., Warner Bros. Entertainment Group. The Box-Jenkins Methodology for Time Series Models, Proceedings of the SAS Global Forum 2013 Conference, Cary, NC: SAS Institute Inc., p. 1-11, 2013.

SILVA, I. N., SPATTI, D. H., FLAUZINO, R. A. Redes Neurais Artificiais para Engenharia e Ciências Aplicadas - Curso Prático, Editora Artliber, 2010.

SANGUN, L., CANKAYA, S., KAYAALP, G.T., AKAR, M., Use of Factor Analysis Scores in Multiple Regression Model for Estimation of Body Weight from some Body Measurements in Lizardfish, Journal of Animal and Veterinary Advances, v.8, n.1, p.47-50, 2009.

SPITZER, J. C. Influences of Nutrition on Reproduction in Beef Cattle, In: MORROW, D. A. (Ed.). Current Therapy in Theriogenology. 2. ed. Philadelphia: W. B. Saunders, pp. 320-341, 1986.

WIDROW, B. and LEHR, M. A. 30 Years of Adaptive Neural Networks: Perceptron, Madaline, and Backpropagation, Proceedings of the IEEE, v. 78, n. 9, p. 1415-1442, 1990. 